\title{
Architecture and Analogous Habitats
}

\author{
ARIANE LOURIE HARRISON \\ Harrison Atelier; GAUD, Pratt Institute
}

Keywords: architcture for nonhumans, machine learning, climate-crisis, species extinction

Harrison Atelier proposes architecture for multiple species in projects that range from pavilion-scale agricultural infrastructure to speculations for new urban ecologies. Such built work represents the application of principles from architectural theories of the posthuman, namely a focus that seeks to integrate habitats for non-humans into architectural design concerns. The Pollinators Pavilion by architect Ariane Harrison, seeks a larger role for architecture in environmental activism and focuses on biodiversity conservation and materials exploration. Harrison Atelier uses artificial intelligence and automated scientific monitoring strategies to create and analyze habitat systems and increase building awareness.

\section{ANALOGOUS HABITATS}

The current sixth mass extinction of species demands new ways of building in support for biodiversity. Species are being extinguished to a large degree because of habitat loss. If, according to the oft-cited statistic that by $2050,68 \%$ of the human population will be living in cities, then we can project further depletion of habitats for non-humans. With urbanization comes a now familiar set of degraded environments: increasing temperatures caused by urban heat island effects, flooding caused by loss of pervious surfaces and poor air quality due to carbon emissions. Urbanization exerts a significant pressure on the non-urban and effectively claims as zones of production (industrialized agricultural and extraction) for the human species those territories which might have supported multiple species. Habitat loss thus continues to drive species loss and increasing tempos of extinction rates.

The impact of human activity on the planet marks a new geological period, the Anthropocene and prompts us to ask whether, on a disciplinary basis, architecture needs to address building for multiple species. Harrison Atelier's position is clear from a programmatic approach: why would we restrict architecture to the design of habitation of one species? We understand that we share the planet with 1.7 million identified species and potentially millions of others that slip unnoticed into extinction due to the anthrocentric environments we produce and reproduce? On a formal level, our work engages affects marking the presence of non-humans. Elsewhere, I have described this as a feral aesthetic: the dual connotations of the term "feral," refering to both mourning and wildness, inscribes non-human presence within a context of threat and loss.

Can architects build alternatives? Analogous habitats refer to man-made artificial ecosystems that can support native biodiversity, in part due to material, structural or functional resemblance to natural ecosystems. Urban and industrial ecosystems can integrate man-made habitats that could function as analogues to natural ecosystems and point to a role for design in reconciliation ecology, defined as "the science of inventing, establishing and maintaining new habitats to conserve species diversity in places where people live, work and play."

Designing habitation for non-humans brings architecture to consider surprising dimensions: native pollinators, for example, inhabit holes and burrows of one centimeter in diameter and ten centimeters in depth. This modest scale points to building cladding as a site for accommodating other species: for example, a façade panel of 1 meter by 1 meter by .01 meters in thickness could contain several hundreds of native pollinator habitats. This tiny scale nests comfortably into the exteriors of our edifices, if we recall how Gothic ornamentation creates perches for bird fauna.

Harrison Atelier addresses the question of building for multiple species from theoretical and practical approaches, grounded in theories of the posthuman articulated since the 1980s in performance, literature and ecology. As I descovered in looking for case studies of architecture for non-humans, once one excluded zoos and industrialized animal farms for their anthrocentric bias, building for species co-existence has few models. Harrison Atelier seeks a larger role for architecture in environmental activism; we offer that architecture, from a materials and design approach, can create habitats for multiple species as a concrete action towards biodiversity conservation. 




Figure 1.Feral Rooftops, Harrison Atelier, 2020.

\section{FERAL ROOFTOPS}

COVID-19 exposed the urgent need for distributed and multiscale networks of urban green spaces, for humans' physical and mental health. A partial solution preceeded the pandemic with changes to the building code through the Climate Mobilizaton Act (CMA): NYC's Local Laws 92 /94 of 2019, mandated "that all new buildings and alterations of existing buildings where the entire existing roof deck or roof assembly is being replaced must provide a sustainable roofing zone covering $100 \%$ of the roof." Between the lines of Local Law 92/94 lies a radically vision for urban rooftops as analogous habitats. This law designates rooftops as not only a new layer of programmed urban space, but potentially a restorative space for multiple species and a secure harbor for biodiversity.

Local Law $92 / 94$ prompts us to view the greened rooftop as a new zone of ecological richness and biodiversity. In the urban imaginary, marginal spaces foster diversity. From Piranesi's ruins outside of Rome that equally sheltered animals, goatherds, pickpockets and beggars, to DC Comics' city of Gotham with its batwinged guardian perched high above, there is a feral logic: the less accessible, less visible or "waste" spaces are inhabitted by outsiders to mainstrean society. Our Anthropocene cityscapes indicate that most species that lie outside of immediate human interaction (either domesticated or food animals) are marginalized and rarely considered as architectural subjects. Yet the margin are repositories for diversity and difference, as discussed by the landscape designer and theorist Gilles Clement as a "Third Landscape," a patchwork of transitional, inaccessible and neglected spaces that, by these same virtues, secure space for biodiversity, becoming, in his terms, a "genetic reservoir for the planet."

In distinction from monocultural roofscapes, Harrison Atelier's project, Feral Rooftops, envisages green roofs as open air reserves of native plants and pollinators, with constellations of field stations that, while monitoring each biodiverse surface, assemble and relay air quality and storm-water sequestration data. Integrating monitoring technology into analogous habitats allows for the constant and patient acquisition of data on biodiversity by machines. A deployment of ecological machine surveillance in this sense could create a more nuanced and scientifically complete understanding of our urban ecosystems, allowing us to understand the striated quality of the urban section. Biodiverse green roofs at New York City's Javits Center function as a new ecological territory, different from the urban park in important ways due to its remove from the traffic of the ground. Javits' roof hosts a rich array of plants and attract hundreds of species of migratory birds, pollinating insects, moths and bats, harboring an impressive biodiversity up high above any of NYC's parks. It is both pragmatic and utopian to ask how dense cities could effectively contribute to what Clement describes as the "planetary garden." 




Figure 2. Pollinators Pavilion, Old Mud Creek Farm, Hudson NY, Harrison Atelier, 2019.

\section{POLLINATORS AND THE PLANETARY GARDEN}

The decline of native and non-native pollinators today poses a major threat to the global agriculture food supply: over $70 \%$ of world crops are pollinated by honey bees, which have collapsed globally due to multiple factors tied to intensive agricultural practices. Global climate change has amplified pollinator population decline, threatening ecosystem resilience and food security at all scales, leading the New York Times to announce in a 2018 feature that "The Insect Apocalypse is Here."

Less widely known is that that familiar and media-friendly honeybee is poor representative for the diversity of pollinating bees. Ninety percent of the planet's 25,000 bee species are native bees, responsible for $75 \%$ of non-agricultural pollination globally. These bees are diverse in size, coloration and foraging preferences and represent the native diversity of each continent: from this perspective, the honeybee is an invasive species imported to North America from Europe. One type of native bee, the mason bee, does the pollinating work of 100 honeybees, yet produces neither hive nor honey. Native bees sustain the majority of non-agricultural plantlife, but have the potential to contribute significantly to agricultural pollination as well: carrying more pollen, transferring fruit pollen at a higher rate, and foraging in more inclement weather than do honeybees. The majority of native are considered "solitary," that is, they do not form hives and social structures. Rather they inhabit singular dwellings, nesting in burrows and tunnels underground. Cavity-dwelling solitary bees make discreet and opportunistic nests in patches of eath, abandoned burrows, holes and reeds; these varied habitats make many solitary bee nesting habitats hard to identify but easy to eradicate.

Despite this critical role, our understanding of some basic aspects of solitary bee biology, including species level distributional and inhabitation patterns, remains incomplete. While Europe has the best described bee fauna globally $(2,000$ species), even this data is surprisingly poor for solitary bee species (of which $60 \%$ were deemed "data-deficient"). The US native bee fauna is far less well described. And adding to the challenges of identification, solitary bees are identified typically in a process called destructive sampling involving trapping, capture and killing the bee subject. Because the elusive nature of solitary bee nesting sites makes monitoring a time-consuming and expensive prospect, and destructive sampling further reduces solitary bee populations, it becomes important that any analogous habitat include an embedded monitoring system, such as a no-kill method for studying solitary bees.

Analogous habitat for solitary bees departs from formats such as "bee hotels," in embedding scientific observation as a program. The architectural dimension highlights the overlooked if not strange presence of non-humans, with the thesis that greater visibility via an architectural format may bring these non-humans into our ethical regard. 


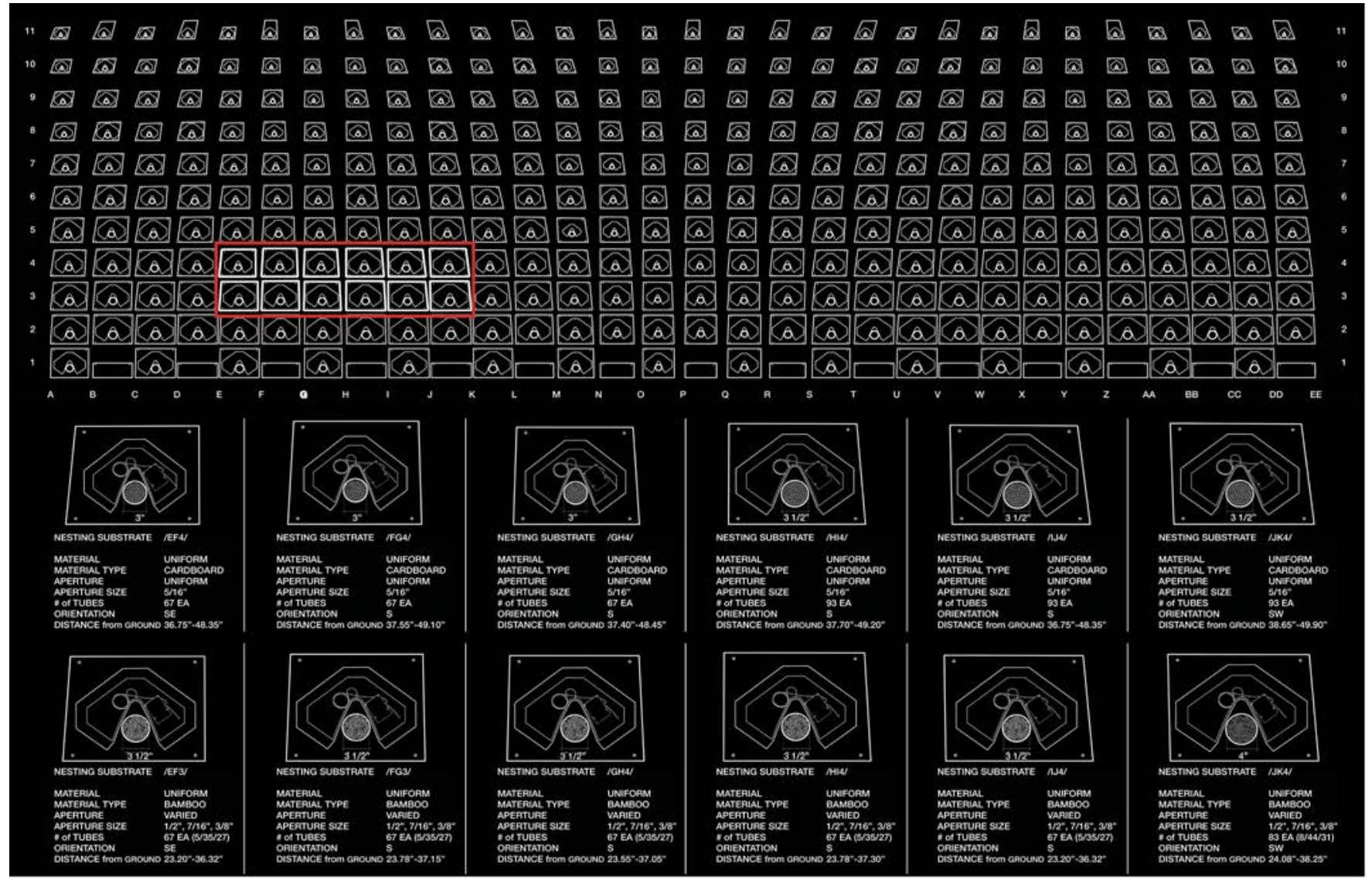

Figure 3. Grid of nesting substrates in Pollinators Pavilion, Harrison Atelier, 2018.

\section{POLLINATORS PAVILION}

Given on the one hand the underappreciated status of these native pollinators, and on the other their increasing importance to food security and agricultural production in the wake of honeybee colony collapse, Harrison Atelier developed the Pollinators Pavilion, a visitors center /analogous habitat for native cavity-dwelling pollinating bees for Old Mud Creek Farm, in Hudson NY. The large organic farm works with Hudson Carbon, an open-source research collaborative that quantifies the effects of regenerative agriculture on soil carbon sequestration. It is estimated that there are about 120 species of native bees likely to congregate in our research zone; half of these are cavity nesting bees, that is to say, potential inhabitants. This particuar context and client led us to ask how an architectural idea - an analogous habitat for native bees- can serve as a new type of agricultural infrastructure by contributing to regenerative farming? Biodiversity contributes to improved management of agricultural land, known as regenerative farming, and has the potential to both reduce net greenhouse gas emissions and to act as a direct carbon sink, with soil contains about 2.5 times more organic carbon than the vegetation.

Recalling the ovoid bristling form of solitary bees' compound eyes, the Pollinators Pavilion is a ribbed-wood structure with
320 handcast UHPC Ductal ${ }^{\circledR}$ panels. The final versons of the panel contains a hole for 30-50 nesting tubes and a cavity housing all the monitoring technology. We placed $152 \mathrm{~mm}$ long nesting tubes (which can accomodate three to six native bee egg cells) of diameters from $3-9 \mathrm{~mm}$ in cardboard, bamboo, glass, wood and other substrates into the panels. Undergoing many tests at 1:1 scale thanks to a uniquely dedicated team, the resulting Pollinators Pavilion's curved surface can be considered a test-bed that reveals nesting preferences. A gridded diagram of the interior evelation demonstrates how panels test a variety of nesting tube substrates nesting tube aperture sizes, orientations to the sun, and nesting heights from the ground level.

Initially inspired by applying rain protection over the nesting tubes, the pointed canopies (or "thorns") evolved in our work to house solar-panel powered monitoring equipment: motion sensors, when triggered by insect movement, prompt an endoscopic camera to photograph the insect. Camera, sensors and microprocessors equip each panel: powered to operate 6 hours a day, we started field studies in September 2020, collecting 1,000 images per day per camera (3 pictures/ min, $6 \mathrm{hr}$ per day). This set of field studies will be extended to the full nesting season in 2020-21, during the four-month nesting season. 




Figure 4. Ductal panel with cardboard nesting tubes and endoscopic camera, Pollinators Pavilion, Harrison Atelier, $2020 .$.

Insect identification lies well outside of the purview of architecture. With the goal of establishing a means of monitoring and eventually identifying pollinating insects, we are indebted to the guidance, advising and collection-access from Dr. Jerome Rozen (American Museum of Natural History), Dr. Kevin Matteson (University of Miami of Ohio) and Dr. Christina Grozinger (Pollinator's Garden, Arboretum, Pennsylvania State University). We assembled thousands of images of Mechachile mendica, Megachile pugnata, Megachile cenruncularis, Megachile campanulae, Hylaeus annulatis, Heriade leavitti and Osmia pumila in Dr. Rozen's Apoid collection at the American Museum of Natural History to create the foundations for an Al model able to identify insect family.

The images harvested by each panel produce a database of photographs to train a machine-learning system to identify native pollinating species without trapping and killing them. Bringing the database into a machine-learning platform, we seek to automate pollinator identification, thereby helping to address biodiversity conservation and fill important gaps in current scientific knowledge of solitary bees and records images of the everyday rhythms of native pollinators. This research has earned support from Microsoft's and National Geographic's Al for Earth programs; models presented at the Microsoft Al for Earth Summit (June 29, 2020) will be shared with the public as open source datasets to contribute to native pollinator identification. Embedding a scientific program of biodiversity conservation within an architecture for multiple species is one way that we see architecture addressing climate crisis.

\section{ARCHITECTURE AFTER THE ANTHROPOCENE?}

The Pollinators Pavilion occupies a prominent role at the entrances of Old Mud Creek Farm and Hudson Carbon at 67 Pinewood Road, Hudson NY. It is visible from the busy Route 9 and draws visitors from the farming, cultural and educational communities in the Hudson Valley. It functions as a field station and analogous habitat for solitary bees, but also as a solstice-watching space, an outdoor classroom, a dance venue, and a way-station on nature tours. This diversity of programs, each with varied connections to our planetary garden, points to inclusivitity - of inhabitats both human and non-human and of multiple functions. Inclusivity equally refers to the crossdisciplinary work required to reach across the anthropocentric divide: one potential for architecture is to offer frameworks to hold biological and computer sciences, machine-learning and hand-casting, digital fabrication and food production together in redefining analogous habitats for the post-Anthropocene. 


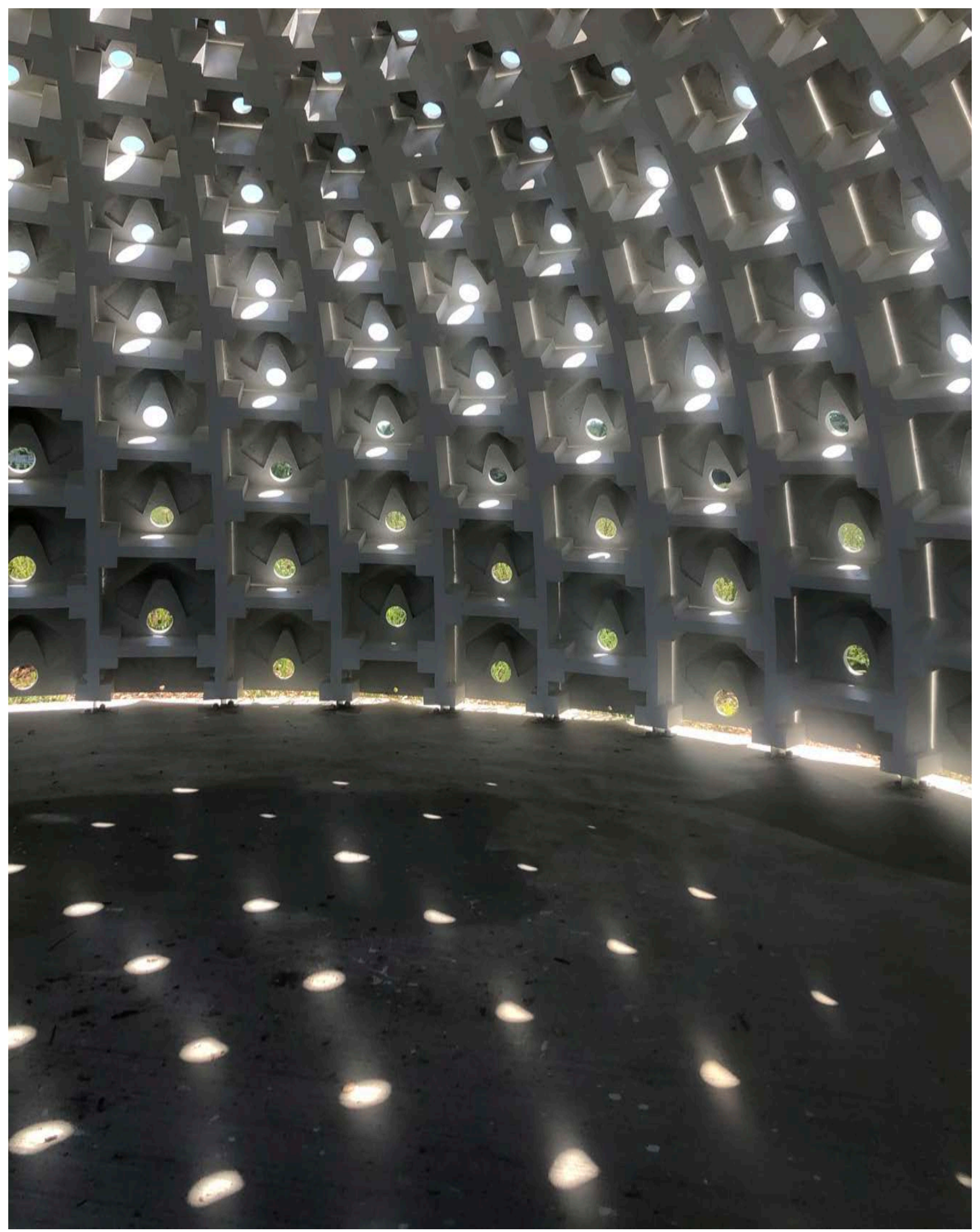






Figure 6. Interior view of nesting tubes and microprocessor, Pollinators Pavilion, Harrison Atelier, 2020.

\section{ENDNOTES}

1. Ariane Harrison, "“Feral Architecture," Aesthetics Equals Politics, ed. Mark Foster Gage, Cambridge, MA: MIT Press, 2019, 255-267.

2. Jeremy T. Lundholm1* and Paul J. Richardson, "Habitat analogues for reconciliation ecology in urbanand industrial environments," Journal of Applied Ecology 2010, 47, 966-975. See also https://www.resilience.org/stories/2016-04-28/ ethics-and-ecosystem-interactions-why-reconciliation-ecology-matters/.

3. See "Charting Posthuman Territory," Architectural Theories of the Environment: Posthuman Territory, ed. Ariane Lourie Harrison (New York: Routledge, 2013), 3-33. An anthology on the posthuman in architecture comprising a collection of sixteen essays by theorists, geographers and historians. I wrote the introductory essay and nine architectural case studies.

4. https://www1.nyc.gov/assets/buildings/pdf/green_roof_solar_II92-n940f2019_sn.pdf. (Retrieved 10/11/2020)

5. Gilles Clement, "The Emergent Alternative," Architectural Theories of the Environment: Posthuman Territory (New York: Routledge, 2013), 258-277.

6. Dustin R. Partridge1,2, , Kaitlyn L. Parkins2, Susan B. Elbin2, and J. Alan Clark1 Bat Activity Correlates with Moth Abundance on an Urban Green Roof, Northeastern Naturalist, 27:1, (2020): 77-89.

7. Brooke Jarvis, "The Insect Apocalypse Is Here," New York Times Magazine Nov. 27, 2018. https://www.nytimes.com/2018/11/27/magazine/insectapocalypse.html

8. Bryan Danforth, Robert Minckley and John Neff, The Solitary Bees: Biology, Evolution, Concervation (Princeton: Princeton Úniversity Press, 2019).

9. The Ductal UHPC Workshop at the Brookklyn Navy Yards, and members of Lafarge-Holcim company Andrew Pinneke, Kelly Henry, and Danny Regad have generously sponsored the material for these panels, as well as their insights and expertise in the production process of 320 hand-cast panels.

10. Harrison Atelier is founded by Ariane Lourie Harrison and Seth Harrison the Pollinators Pavilion project has been led by Yuxiang Chen, a Pratt MS Architecture (2018) graduate along with Pratt GAUD graduates Eileen Xu, NaiHua Chen, Zongguan Wang, Spring Wu, Brad Li, Daniel Longoria and Yale SoA graduates Victoria Ereskina and Matthew Bohne.

11. We are indebted to Dr. Jerome Rozen and Lance Jones at the American Museum of Natural History, New York, for the hours of discussion and time to photograph the Apoidea collection. Our network of scientific advisors includes Dr. Jerome Rozen (Curator Emeritus, Apoidea Collection at the American Museum of Natural History); Dr. Kevin Matteson (Dir. Graduate Programs for Social and Ecological Change, Miami University, Ohio), Christina M. Grozinger

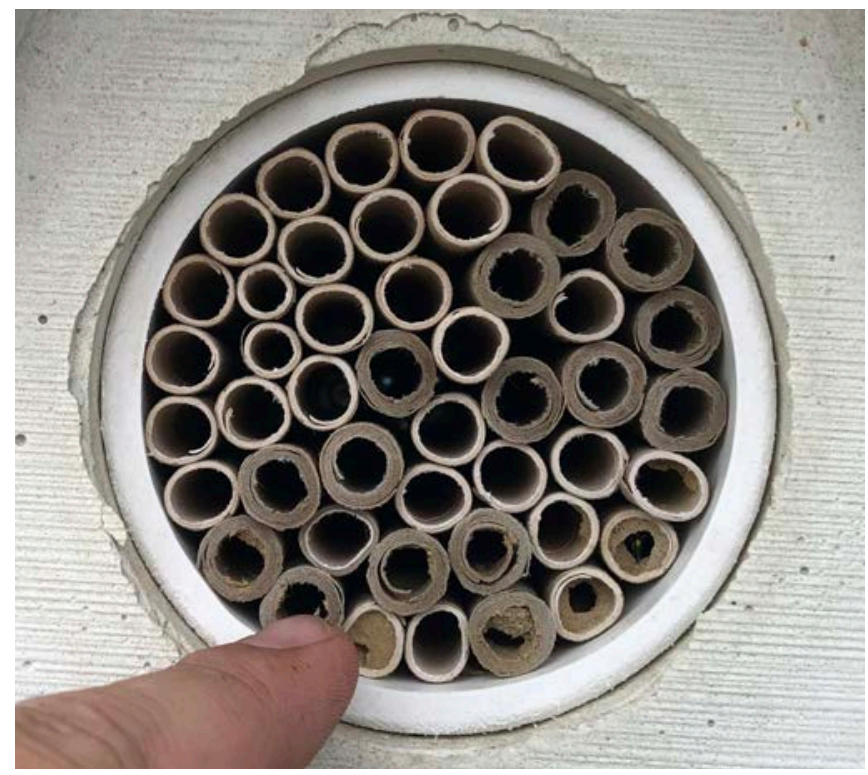

Figure 7. Exterior view of panel indicating nesting tubes occupied by pollinating bees, Pollinators Pavilion, Harrison Atelier, 2020.

(Distinguished Professor of Entomology and Director, Center for Pollinator Research at the Huck Institutes of the Life Sciences, Pennsylvania State University); Natalie Boyle (Center for Pollinator Research at the Huck Institutes of the Life Sciences, Pennsylvania State University) and Sam Droege (USGS Patuxent Wildlife Research Center)

12. This innovative panel system was awarded third place at the New York City Media Lab Tech Expo of 2018; Pratt faculty research grants, Pratt research Open House awards in 2019 and 2020, as well as Microsoft and National Geographic Al for Earth grants. 